\begin{tabular}{|c|c|}
\hline & $\begin{array}{c}\text { European Association for the } \\
\text { Development of Renewable Energies, Environment } \\
\text { and Power Quality (EA4EPQ) }\end{array}$ \\
(ICREPQ'12) & International Conference on Renewable Energies and Power Quality \\
&
\end{tabular}

\title{
Very short-term load forecast for demand side management in absence of historical data
}

\author{
Neusser, Lukas ${ }^{1}$, Canha, Luciane N. ${ }^{1}$, Abaide, Alzenira ${ }^{1}$ and Finger, Maicon ${ }^{1}$ \\ ${ }^{1}$ Centro de Estudos em Energia e Meio Ambiente \\ Universidade Federal de Santa Maria \\ Av. Roraima, 1000 - Campus Camobi - Santa Maria - RS - Brazil \\ Phone: +55 5532209541 - e-mail: lukasneusser@hotmail.com /lucianecanha@gmail.com / alzenira.abaide@ gmail.com
}

\begin{abstract}
Load forecasting plays an important role in today's electricity grid, due to the presence of distributed generation. In this paper, various methods for short-term load forecasting are presented with the purpose to serve as tool to operate within a demand side management system. The need for large amount of historical data is avoided, opening the possibility for immediate use by customers without recorded load history. Widely distributed, such system can increase the reliability of the modern grid. The results showed that the HoltWinters forecasting procedure give better results in comparison to neural networks with gradient descent, principally if the load rises fast in the early morning hours.
\end{abstract}

\section{Keywords:}

Demand side management, load forecasting, time series analysis, artificial neural networks, easy use.

\section{Introduction}

Today's electricity grid is walking in fast steps toward a grid with fully integrated distributed generation. The new distributed energy sources are almost based on renewable energy sources, mainly wind and solar, which have small power rating. Located near the consumers, they inject their intermittent power in a historical underscored grid, mostly operating on its limits. There is immediate need to integrate all those distributed renewable energy sources, without bringing down the grid. To avoid supply bottlenecks, the instantaneous demand must be adjusted to the power availability at the same moment. That means that there must be a system antecipation of the needs from the consumers before they arrive, and capable to take action, insight of a generation/load mismatch. Therefore, a modern demand management system has to achieve three main goals:

- Demand shedding - the old demand response solution. The new focus is only to shed as the last resort, when other measures miss the desired results;
- Demand shifting - being aware of the future status of the system, load can be shifted forwards (most and easy cases) or backwards;

- Load curve shaping - real time demand fine tuning, also known as "flexible load curve";

Such a system, described above, needs a core algorithm to forecast the demand. Much research has been done, and a relative wide range of approaches has been proposed. Most of them based on neural networks [1][2][3], or time series analysis such as ARIMA or SARIMA models [4]. Interesting work was the fading-memory Kalman filter algorithm [5]. A comparison of different methods, including the Holt-Winters exponential smoothing is found in [6]. However, most of the above-cited approaches have a main problem: the need of large amounts of historical data, as minimum and maximum daily temperatures and load curves from the past. No practical use of such system can be expected on "normal" consumers, that means, where only a simple $\mathrm{kWh}$ meter is installed today (no demand history available).

This paper presents the early results for a more comprehensive system that is under development by the CEEMA (Centro de Estudos em Energia e Meio Ambiente) from the Universidade Federal de Santa Maria, Brazil. Research is underway for a complete realtime distributed demand side management system, planned for medium to large sized educational, government or business buildings.

\section{Problem identification and objectives}

Although a modernization of the electrical system is underway in great parts of the world, including Brazil, the majority of the consumers still have old $\mathrm{kWh}$ meters installed. The only historical data available are the monthly energy consumption. So, to include a forecast capability in a demand management system, to be installed for such a customer, a special approach is 
needed. In the present case, load forecast means estimate the future load a few steps ahead in time. The system proposed must be capable to start immediately, and adapt automatically from the ingoing data, independently from the consumers nature and behavior.

To obtain a real data set for research, an intelligent energy meter (smart meter) was installed on the substation from the Technology Center engineering laboratories, on the campus from the University of Santa Maria, to register the energy load in 15-minute intervals. As result, we obtain the typical load curve, for this site, for workdays, shown in figure 1 .

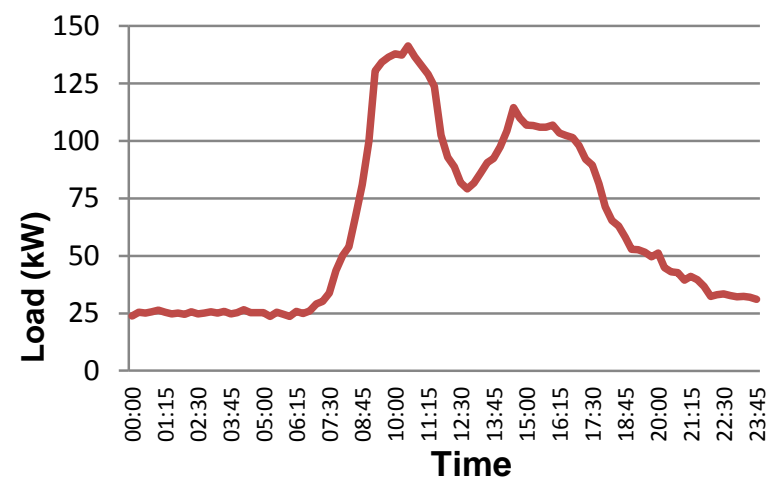

Figure 1: Typical daily load curve, Technology Center Engineering Laboratories substation

The load's typical behavior is a fast rise in the morning, a mid-day valley, and a most slowly decay on the end of the day. The smart meter is providing data since June 2011, giving the necessary data to trains and validate the forecast algorithm (over 4000 measures, 96 per day, in 15minute intervals).

\section{The Holt-Winters forecasting procedure}

The Holt-Winters forecasting procedure [7], is an exponential smoothing method for univariate time series containing trend and seasonal variation. In the present case, the seasonal variation is on daily basis, because the load rise and fall occurs every workday approximately at the same time. Meteorological variations or long term seasonal trends are reflected directly by the demand series itself, due its slow changing nature.

The value of the Holt-Winters forecasting procedure has already been shown by Taylor and McSharry [8].

The great advantage of this method is the need of, at last, only one day of past data.

The future load (one-step ahead) is given by:

$$
\mathrm{y}_{\mathrm{t}=} \mathrm{R}_{\mathrm{t}-1}+\mathrm{G}_{\mathrm{t}-1}+\mathrm{S}_{\mathrm{t}-\mathrm{L}}
$$

Where:

$\mathrm{y}_{\mathrm{t}}$ is the load estimated for the present time slot initialized with the most recent load measure, obtained at t-1 (15 minutes ago).

$\mathrm{R}_{\mathrm{t}-1}$ is the estimate of the deseasonalized level from the past time slot. Is this case the time slot is 24 hours, and initialized with the mean load from the past 24 hours (mean on 96 fifteen minute interval values);

$\mathrm{G}_{\mathrm{t}-1}$ is the estimate of the trend from the past time slot initialized with zero, because no trend observed.

$\mathrm{S}_{\mathrm{t}-\mathrm{L}}$ is the estimate of the seasonal component, from the past season (in this case the past day). The initial value is given by the difference between the load from the same moment on the past day and the mean load from the last 24 hours;

The estimates are updated as follows:

$$
\begin{aligned}
R_{t} & =\alpha\left(y_{t}-S_{t-L}\right)+(1-\alpha)\left(R_{t-1}+G_{t-1}\right) \\
G_{t} & =\beta\left(S_{t}-S_{t-1}\right)+(1-\beta) G_{t-1} \\
S_{t} & =\gamma\left(y_{t}-R_{t-1}\right)+(1-\gamma) S_{t-L}
\end{aligned}
$$

The value of $S_{t-1}$ in (3) is initialized with the same value of $\mathrm{S}_{\mathrm{t}-\mathrm{L}}$.

In the above formulas (2), (3) and (4), $\alpha, \beta$ and $\gamma$ are smoothing constants.

Using the available data set (over 4,000 samples), each constant was varied between 0 and 1 , and the MAPE (Mean Absolute Percentage Error) was observed.

Figure 2 shows the comparison between the real load, estimated load and percentage error based on data measured on June 28, 2011

The best results were obtained with the smoothing constants $\alpha=0,7 \beta=0$ (no trend) and $\gamma=0,35$, resulting in a MAPE (Mean Absolute Percentage Error) equal to $4.93 \%$.

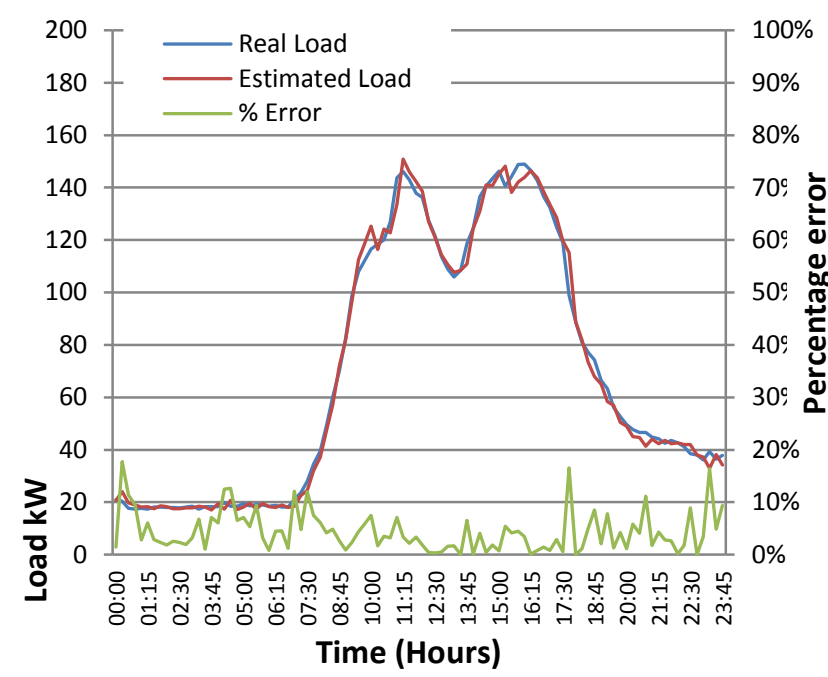

Figure 2: Comparison between the real load, estimated load by exponential smoothing and percentage error 


\section{Artificial Neural Networks forecasting method}

Another approach to "track" time series is the use of a focused time lagged feedforward network (TLFN). The difference to the normal multilayered perceptrons is the incorporation of time, represented implicitly by a shortterm memory structure. Haykin [9], refers to the TLFN as a temporal pattern recognition method that "process patterns that evolve over time, with the response at a particular instant of time depending not only on the present value of the input but also on its past values". Figure 3 represents such network.

Every neuron has an associated transfer function applied to the sum of the product of the entries and the respective weights.

Always when a new load value appears on the timeline, the previous output from the network is compared with the new value, and the weights are updated backwards in a process called back propagation learning.

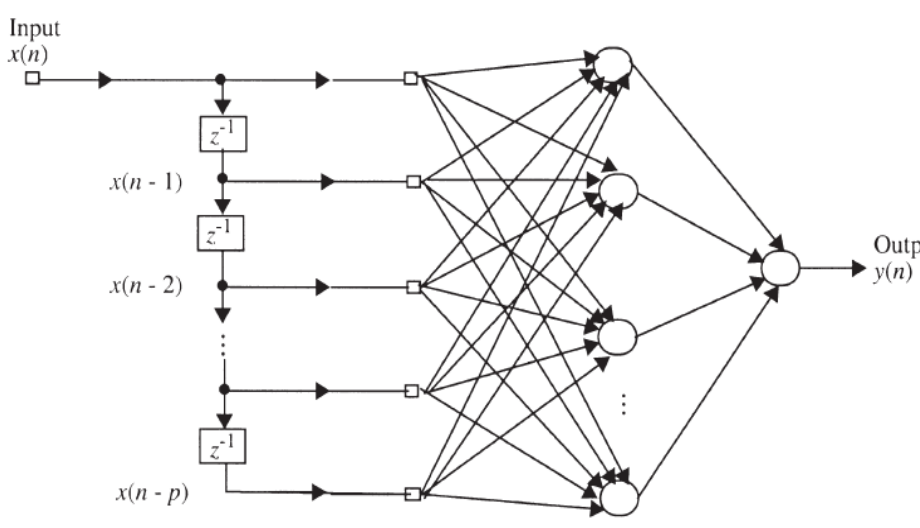

Figure 3: Focused time lagged feed forward network

For the presented case, experiences were made on two layered neural networks: one output layer, with a single neuron, and one hidden layer with variable number of neurons. The number of neurons in the hidden layer were successively increased, and the type and number of entries too.

The transfer function for the output layer was chosen to be linear, as shown in equation (5) below:

$$
y_{k}=\alpha\left(\sum_{j=1}^{m} w_{k j} y_{j}\right)+b_{k}
$$

In addition, the transfer functions in the hidden layer were chosen to be sigmoid (6):

Where:

$$
y_{j}=\frac{1}{1+e^{-v_{j}}}
$$

$$
v_{j}=\sum_{i=1}^{m} w_{i j} x_{i}+b_{j}
$$

The initial random weights between 0 and 1 , are backwards updated depending on the output error:

$$
e_{k}=L-y_{k}
$$

Where $\mathrm{L}$ in (8) is the real measured load.

$$
\begin{aligned}
& w_{k j}(t+1)=w_{k j}(t)+\eta\left(e_{k} y_{j}(t)\right) \\
& w_{i j}(t+1)=w_{i j}(t)+\eta\left[e_{k} w_{k j} y_{j}(t)\left(1-y_{j}(t)\right)\right]
\end{aligned}
$$

The equations (9) and (10) shows how the weights are update in a method called method of steepest descent.

Based on the above rapidly explained network formulas, simulations were made, whose results are in the table 1 , below. It is interesting to observe that the number of entries and hidden neurons has no influence over the MAPE. It appears that the MAPE is only influenced by the "quality" of the entries (where they are located in time).

Figure 4 shows the comparison between the real load, estimated load by the focused time lagged feedforward network and percentage error, based on data measured on June 28, 2011. The method resulting in this graph was the last of table 1 (Three previous loads + four loads of four previous days).

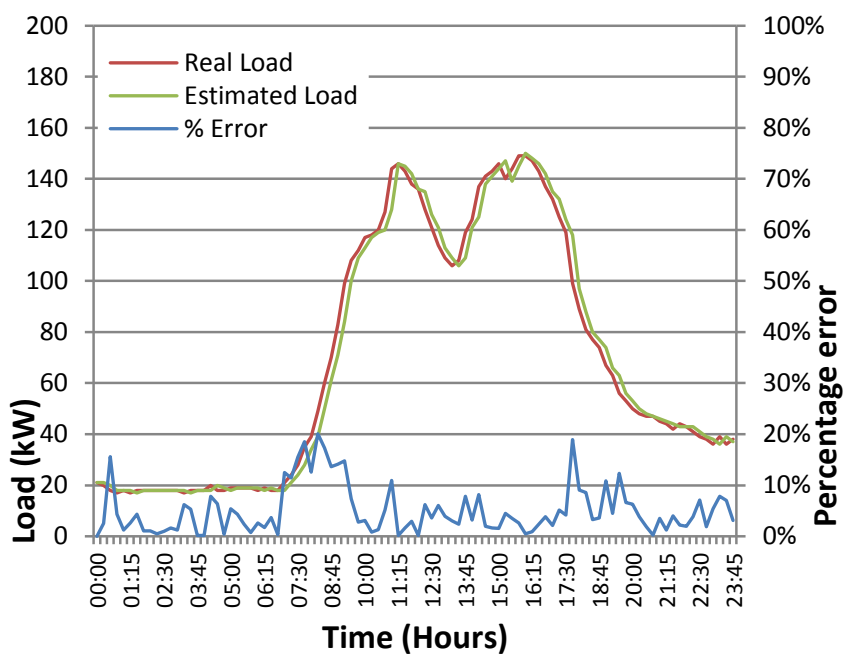

Figure 4: Comparison between the real load, estimated load by neural network and percentage error

Table 1: Summary of simulations made and the resulting MAPE

\begin{tabular}{lcc}
\hline Type of entries & $\begin{array}{c}\text { Nr. hidden } \\
\text { neurons }\end{array}$ & MAPE \\
\hline Four previous loads & 4 & $5.1 \%$ \\
\hline Five previous loads & 5 & $5.1 \%$ \\
\hline Six previous loads & 6 & $5.1 \%$ \\
\hline Ten previous loads & 10 & $5.1 \%$ \\
\hline Twenty previous loads & 10 & $5.0 \%$ \\
\hline $\begin{array}{l}\text { Ten previous loads + ten } \\
\text { previous loads one day before }\end{array}$ & 10 & $5.0 \%$ \\
\hline $\begin{array}{l}\text { Three previous loads + three } \\
\text { loads of three previous days }\end{array}$ & 4 & $4.7 \%$ \\
\hline $\begin{array}{l}\text { Three previous loads + four } \\
\text { loads of four previous days }\end{array}$ & 5 & $4.6 \%$ \\
\hline
\end{tabular}




\section{Conclusions:}

In this paper, preliminary results in the search of a robust, fast and easy to use algorithm for load forecast are presented. The surprise was that the number of hidden neurons in a focused time lagged feed forward network had only limited impact on the MAPE. Networks that include data from a few previous days have lightly better results. However, compared to the Holt-Winters forecasting procedure, there are only a very small error improvement.

Keeping a closer eye on the data, it reveals that the HoltWinters method is better, because when the load rises fast in the early morning hours, it returns lower errors in comparison to the similar neural network. On the other hand, the fact that the Holt-Winters method look back only one day, can introduce large errors if the previous day was abnormal (for example a cold day followed by a day with higher temperatures).

The above-mentioned facts must be seen in light of the methods used: focused time lagged feedforward network with steepest descent learning algorithm or Holt-Winters exponential smoothing, with no trend. There were chosen to keep the processing fast and simple, to match the goal for a real-time load management.

However, as advantages of such algorithms can be cited:

- $\quad$ No need of load data, more than a week ago;

- No need of long computational time, for training;

- The need of only a few logic and calculus steps, to make a forecast;

More work must be done to fine-tuning the Holt-Winters method. In addition, for the neural networks, more days backwards must be included. Of course, not too much days, otherwise the goals are missed. Eventually other faster optimization algorithms must be tested.

To achieve the proposed goals, the need of historical data must be limited, perhaps to a maximum 5 workdays. This means that, once installed on a consumer, the system can operate fully within a week.

\section{References:}

[1] Steinherz, Henrique H., Pedreira, Carlos E., Souza, Reinaldo C. "Neural Networks for Short-Term Load Forecasting: A Review and Evaluation". IEEE Transactions on Power Systems, Vol. 16, Nr. 1, February 2001.

[2] Liu,K., Subbarayan,S.,Shoults, R.R., Manry, M.T., Kwan, C., Lewis, F.L., Naccarini, J. "Comparison of very short-term load forecasting techniques". IEEE Transactions on Power Systems, Vol. 11, Nr. 2, May 1996.

[3] Hsu, Yuan-Yih, Yang, Chien-Chuen. "Design of artificial neural networks for short-term load forecasting. Part II: Multilayer feedforward networks for peak load and valley load forecasting”. IEE Proceedings-C, Vol. 138, Nr. 5, September 1991.
[4] Andrade, Luciano C.M., Silva, Ivan N. "Very Short-Term Load Forecasting Based on ARIMA Model and Intelligent Systems". ISAP '09. 15th International Conference on Intelligent System Applications to Power Systems, 2009.

[5] Sargunaraj, S.,Gupta, D.P.S., Devi, S. "Short-term load foracasting for demand side management". IEE Proceedings in Generation Transmission and Distribution, Vol. 144, No. I , January 1997

[6] J. W. Taylor, L. M. de Menezes, and P. E. McSharry, "A comparison of univariate methods for forecasting electricity demand up to a day ahead" Int. J. Forecasting, vol. 22, pp. 116, 2006.

[7] Chatfield, Christopher. "The analysis of time series: an introduction”. pp 78, 6th ed. Chapman \& Hall. 2004.

[8] Taylor, James W., McSharry „Patrick E.” Short-Term Load Forecasting Methods: An Evaluation Based on European Data" IEEE Transactions on Power Systems, Vol. 22, Nr. 4, November 2007.

[9] Haykin, Simon. Neural networks: a comprehensive foundation. 2th Edition. Prentice Hall. 1999. 